\title{
Editorial
}

\section{Providing primary care for people with serious mental illness}

Trying to engage primary care in thinking about the care of people with psychosis can be an uphill task. Most general practitioners do not see it as an important issue because the numbers seem so small. It is rare in the scheme of things, however, since $80 \%$ of first episodes of psychosis occur in people between the ages of 16 and 30 years, this builds to a lifetime prevalence of $3.4 \%$ (Perala et al., 2007). But it is not, I would argue, an issue of numbers, but of consequences, because many people who live with serious mental illness develop significant physical health problems.

There is a substantial evidence base that people with psychosis die sooner than the rest of the population. Hennekens' recent review of mortality in schizophrenia found a $20 \%$ reduced life expectancy compared with the general population (Hennekens et al., 2005). Although people with schizophrenia were 10 to 20 times more likely than the general population to commit suicide, more than two-thirds of people with schizophrenia died of coronary heart disease, compared with approximately one-half in the general population.

There are, of course, a number of contributory factors to these statistics, some of which, at face value, may seem beyond the control of primary care. Second generation antipsychotic drugs, for instance, have significant side effects including weight gain, dyslipidemia and diabetes. Other risk factors for cardiovascular illness such as poor diet, lack of physical activity and much higher smoking rates than the general population, are issues that primary care is better placed to address (Connolly and Kelly, 2005), particularly when you remember that people with serious mental illness consult more frequently than those without (Nazareth et al., 1993).

However, evidence from the United Kingdom and United States suggests that primary care has not traditionally seen health promotion and prevention as part of its role with people with psychosis (Druss et al., 2001; Kendrick, 1996). The consequences of this were vividly demonstrated in a 2005 report by the Disability Rights Commission based on a review of the primary care records of 1.7 million primary care patients. This found that women with schizophrenia were less likely to have had a cervical smear in the previous five years (63\%) compared to the general population $(73 \%)$ and that $68 \%$ of people with schizophrenia and heart disease had a recent cholesterol test compared with $80 \%$ of the remaining population with heart disease (Disability Rights Commission, 2005). The better news is that one of the potential benefits of the pay for performance scheme, the Quality and Outcomes Framework, introduced into the United Kingdom in 2004, is that annual physical health checks for people with serious mental illness are now a routine part of primary care. This should mean that primary care may at last begin to provide equivalent physical health care for people with and without serious mental illness, leading to better physical outcomes in the longer-term.

The latest challenge in this area for primary care both in the United Kingdom and across northern Europe, Canada and Australia, is to provide more and better care for young people with psychosis who have been seen and treated by Early Intervention Services. This group of individuals will have received gold standard care for up to three years from newly established community based teams that provide early multidisciplinary phase specific treatments such as cognitive behavioural and family therapy. Most will have been diagnosed at an earlier stage in their illness and treated more proactively than their predecessors. Many of the Early Intervention Services were set up during the last five years, 
which means that the most recently diagnosed individuals with psychosis are only now being discharged back to primary care. They will have expectations of continued high quality health care. We may not even have noticed they hadn't consulted us for a while. Many will be taking drugs that put them at higher risk of cardiovascular events. We may miss the discharge letter or the significance of the diabetogenic drugs prescribed to an already overweight 22-year old. They will also be looking for help in terms of their continuing social recovery, getting back to work or into education, at a time when those without the double bind of stigma and side effects are struggling to do so. There is a recipe here for at best, unmet expectations and disappointment and at worst, covert neglect of an illness iceberg of disastrous proportions.

Yet, we already have systems in place to work with this new generation of young people with psychosis. Annual health checks, perhaps something we currently associate with the 'middle aged,' need to begin early. The Royal College of Psychiatrists has recently recommended that people on second generation antipsychotics should have their body mass index, blood pressure, smoking status, lipids and glucose checked on an annual basis (Royal College of Psychiatrists, 2009), all components of the Quality and Outcomes Framework review. Primary care, by nature of its longitudinal relationship is also well placed to encourage optimism and hope for young people and their families, particularly in terms of outcomes. A recent longitudinal international study of recovery from psychosis found that as many as $56 \%$ of patients recovered from psychotic illnesses, a minority even years after the initial diagnosis (Harrison et al., 2001). This is not, however, a message that we routinely give (Lester et al., 2005).

There are a series of tensions here: treat young people as if they have a chronic illness (which may remit or resolve) and as if they were much older than they look in terms of their cardiovascular health, whilst simultaneously not neglecting those who have lived with the diagnosis for decades and may already be living with the consequences. This should not be beyond the wit of the wider primary care team. As Iona Heath has so eloquently stated - 'Uncertainty, contradiction and complexity are the stuff of general practice and the measure of much of its fascination for us' (Heath, 1999, p. 565). It is, however, an urgent and universal challenge with our patients paying the price of a failure to engage.

Helen Lester

Professor of Primary Care

NPCRDC, 5th Floor Williamson Building

Oxford Road, Manchester M13 9PL, UK

Email: Helen.Lester@manchester.ac.uk

\section{References}

Connolly, M. and Kelly, C. 2005: Lifestyle and physical health in schizophrenia. Advances in Psychiatric Treatment 11, 125-32.

Disability Rights Commission. 2005: Equal treatment: closing the gap. London, UK: DRC.

Druss, B., Bradford, W., Rosenheck, R. et al. 2001: Quality of medical care and excess mortality of older patents with mental disorders. Archives of General Psychiatry 58, 565-72.

Harrison, G., Hopper, K., Craig, T. et al. 2001: Recovery from psychotic illness: a 15 and 25 year international follow up study. British Journal of Psychiatry 178, 506-17.

Heath, I. 1999: Uncertain clarity: contradiction, meaning and hope. British Journal of General Practice 49, 651-57.

Hennekens, C., Hennekens, A., Hollar, D. and Casey, D. 2005: Schizophrenia and increased risks of cardiovascular disease. American Heart Journal 150, 1115-21.

Kendrick, T. 1996: Cardiovascular and respiratory risk factors and symptoms among general practice patients with longterm mental illness. British Journal of Psychiatry 169, 733-39.

Lester, H.E., Tritter, J.Q. and Sorohan, H. 2005: Providing primary care for people with serious mental illness: a focus group study. British Medical Journal 330, 1122-28.

Nazareth, I., King, M. and Haines, A. 1993: Care of schizophrenia in general practice. British Medical Journal 307, 910.

Perala, J., Saarni, J., Saarni, S.I. et al. 2007: Lifetime prevalence of psychotic and bipolar disorders in a general population. Archives of General Psychiatry 64, 19-28.

Royal College of Psychiatrists. 2009: Physical health in mental health. Final report of a scoping group. London, $\mathrm{UK}$ : RCP. 